\title{
Study on Nanshan Scenic Spot Tourism Crafts Development Idea
}

\author{
Qing Li \\ Art and Design Department \\ School of Humanities \\ Yantai Nanshan University \\ Yantai, Shandong, China 265713
}

\begin{abstract}
Tourism crafts industry is one of the signs of rapid development in tourism economy. Its prosperous development can not only promote development of economy in tourist attraction, but also bring prosperity to art and culture market and invisibly boost publicity of tourist attraction, having inestimable potential economic benefit. However, making a general survey of the whole tourism crafts market of Nanshan scenic spot, and it is really difficult to find tourism crafts which can represent local cultural value and art features. There is an eyeful of goodies with numerous names in local crafts market, but most of them are imported goods and are sold across the whole country. Therefore, it is difficult to arouse tourist's desire to purchase and it is extremely urgent to exploit tourism crafts representing local cultural spirit of Nanshan. This paper intends to analyze and argue from the three aspects of abundant Buddhist resources and advantaged historical and cultural resources of Nanshan scenic spot and cultivation of talents in Art and Design Department, Nanshan University, which is of the same breath and branches with Nanshan scenic spot, put forward several thoughts on exploitation of crafts on the basis of discussion on formation of local tourism crafts' development bottleneck and hope to provide references for prosperous development of Nanshan tourism.
\end{abstract}

Keywords-Nanshan; tourism crafts; culture; development

\section{INTRODUCTION}

Like a new force suddenly rising, Longkou Nanshan tourist attraction is located in Yantai, one of the first batch of coastal open cities in China. It lies against the mountain and near the ocean with exquisite scenery. It is both humanity and natural ecological landscape forged by Nanshan Group which belongs to the national top 500 enterprises, combining tourism, sightseeing, leisure, nourishing of life, entertainment and conference. It passes dual authentication of 1509001 international quality management system and 15014001 international environment management system in recent years successively. It is defined as $5 \mathrm{~A}$ class tourist attraction by National Tourism Administration in 2011. Witty and beautiful natural landscape and religious historical culture with deep connotation constitute advantaged tourism resources of Nanshan. Leaders of Nanshan Group have strategic insight and pioneering spirit and they aim at the opportunity of our country encouraging development of ecological tourism economy. Since 1990s, tourism industry has been regarded as enterprise's new economic increase point and pillar industry of development. After sufficient survey and analysis on developed foreign countries of tourism, several scenic spots of Nanshan Theme Park, Chinese Historic Religious Cultural Park and East China Sea tourist resort are built in simple and elegant Lushan. In recent years, with continuous carrying out of various folk tourism activities and cultural and religious activities in the scenic spot, a lot of travel enthusiasts go to the trouble of traveling a long distance to come here. They come here to pray and make a wish, or go hiking with each other, or go sightseeing. The miracle of 100 thousand tourists in a single day has been made in spring temple fair, invisibly pushing forward rapid development of tourism economy in Nanshan scenic spot.

As everyone knows, tourism economy relies on tourist's consumption in travel activities, which is mainly displayed in the six aspects of food, accommodation, transportation, tour, purchase and entertainment. Besides tasting all kinds of snacks in sightseeing place and experiencing exotic folk custom and traditional culture, "purchase" is also an indispensable part of tourist's travel activities. They can extend aesthetic experience in travel to subsequent life through purchasing tourism crafts with regional features, or regard these crafts as entity capital to brag to relatives and friends, enriching people's spiritual and cultural life. The data shows that purchase consumption occupies $50 \%$ or more of local tourism income in many developed countries of tourism. It can be said that whether tourism crafts industry is developed or not has become an important sign of development level of tourism. Therefore, developing and designing tourism crafts with regional culture features have inestimable effect on boosting development of tourist attraction's economy and they have broad prospects and enormous market.

\section{DEVELOPMENT STATUS OF TOURISM CRAFTS IN NANSHAN SCENIC SPOT}

\section{A. Lack of Nanshan Scenic Spot's Regional Features}

Tourism crafts full of regional charm are signatures reflecting long history and ancient culture of tourist attraction. As tourism commodities, besides economic value and collection value, they can make people learn by heart and they are helpful for cultural promotion of the scenic spot. Throughout famous foreign and domestic tourist attractions, their sharp risings are all accompanied with prosperous 
development of crafts as local business card. For instance, silk of Suzhou and Hangzhou has beautiful colors and light texture and is sold at home and abroad as oriental artistic flower in Han Dynasty with the brand of national culture; duplicates of Terracotta Warriors in Xi' an are vivid and exquisite, and they can bring heavy historic and cultural atmosphere as indoor decoration and furnishing, making a harmonious and orderly home; Thangka which is used to display religious content uses sophisticated material and bright colors and displays rich snow area style of Tibetan areas, being loved by local tourists very much. In addition, tri-colored glazed pottery of the Tang Dynasty in Luoyang, Henan, silk parasol in West Lake of Hangzhou, folk paper-cut in Xi'an and tie-dye in Yunnan are all inheritance and reproduction of civilization, history and culture in travel place, and they bring huge economic benefit to development of local tourism industry, demonstrating wisdom and diligence of local laboring people. So to speak, what people purchase are not only commodities, but unique cultural and national features in various travel activities.

We can again look at tourism crafts market of Nanshan scenic spot. Scattered booths of different size are full of beautiful things in eyes, such as various kinds of pearl necklace, bracelet, shell accessories, sea snail, mascot, crystal balls and other series of sea crafts. It happens that there is a similar case. The writer has seen these commodities in crafts market of Taihang Mountains tourist attraction in Henan, Qingdao and other coastal cities. No matter it is raw material or processing technology, they are the same as commodity of the same classification in inland market. What's more, we can see camphor wood comb and sandal wood beads which are available everywhere in Wuyuan scenic spot, Jiangxi, kites and peachsword from Weifang small commodities market in Shandong, embroidery and plush toy from Yangzhou, Jangsu and other imported products around Nanshan Park built near beautiful Lushan. It is not excessive to use all sorts and having everything available to describe here. These products can be called popular goods of dependable quality and they are sold on crafts market all around the country, so why do tourists take the trouble of traveling a long distance to come here to purchase these products without any regional features? Therefore, tourism crafts market of Nanshan is extremely disproportionate with local tourism industry under prosperous development. It is important to explore cultural features of crafts in development of competitive tourism industry.

\section{B. Indifference in Concept and Lack of Unified Planning}

Through survey on Nanshan tourism, we can see that Nanshan Group pays great attention to constructions of each hardware in tourist attraction, especially planning and construction of each traveling route. Only the traveling route of religious culture in Nanshan scenic spot itself includes a series of scenic spots of Nanshan zen temple, Nanshan monastery, the giant Buddha of Nanshan, Spirit Source Temple and Perfume Nunnery, let alone construction of entertainment facilities along the four traveling routes of Chinese Historic Cultural Park, Theme Park and Happy Canyon, East Sea Seashore Tourist Resort and golf tour experience. Besides ancient temple of thousands of years handed down in Jin, Tang, Song, Yuan, Ming and Qing
Dynasties, ancient building complex full of atmosphere of humanism is also built near the mountain, inside which there are tortuous, spectacular, simple and elegant pavilions and quite perfect service facilities of various kinds, like conference center, hotel, sea view hotel, fitness center and pub.

During the process of building Nanshan into a large multifunction tourist area, exploration of tourism crafts carrying cultural connotation does not arouse enough attention from people. Indifference in concept leads to lag of the pace of action. Apart from insufficient funding, scale concept is not formed in specific research and development, production and sales section. Tourism crafts run their own course in market. It is undoubted that it is difficult to form brand crafts with local features.

\section{Rough and Inferior Quality and Insufficient Artistry}

After all, tourism crafts are a kind of commodity in circulation and they should withstand repeated playing and examination of tourists, requiring that crafts should reflect folk custom of traveling place and have good quality at the same time. Most of craft workshops around Nanshan separate production and management. Crafts made by imitation are not only of single variety and are all in the same key, but also have poor quality and lack of exquisite thought. Products' added value of technology and art is low. In start phase of development, crafts can neglect pursuit of scale effect, but workmanship and artistic pursuit have to stand up to scrutiny. Development of tourism crafts in Wuyuan, Jiangxi has done a great job in this aspect, from which we should learn. Due to moist climate in the whole year, this place abounds with natural camphor wood. It has fine and exquisite texture and refreshing rich fragrance, which can repel mosquito and mildew, take drugs and have antiseptic effect. Based on these, local crafts developers use camphor wood as raw material to make various wonderful wooden comb, wooden chopsticks, brush pot, trousseau, tea table, wardrobe and other artistic and practical crafts. In addition to this, local skillful craftsman elaborately designs a series of delicate and beautiful ornaments, like Maitreya Buddha, zodiac, background hanging, cinnabar, bead necklace and bracelet. They are endowed with good moral of attracting wealth, enjoying ease and comfort, satisfactory, as one wish and so on through careful and exquisite carving and various independent and continuous decorative patterns. They have exquisite and simple modeling and high collection value. Therefore, although camphor chest and tables and chairs have mass volume, they win great love from tourists.

Scanning widely over jagged crafts of Nanshan scenic spot, they lack of a kind of spirit to do exquisitely, finely and deeply, which is contained in bone. This kind of spirit can not be achieved in one day. It needs professional talents' constant inheritance and innovation with artistic talent, great efforts of several generations and the spirit of doing slowly and steadily and keeping improving. 


\section{DEVELOPMENT IDEA OF TOURISM CRAFTS IN NANSHAN SCENIC SPOT}

\section{A. Dig Humanity Resources of Buddhism and Forge Crafts Features}

In essence, tourism crafts are reflection of regional folk culture. During the process of shopping, people taste earthy and natural folk custom and humanity connotation which are different from other things of various places, thus satisfying their exploration mind of seeking change and innovation. The more unique the culture is in crafts, the more attractive crafts are to people. For instance, Mogao Caves in Dunhuang has the good reputation of "World Cultural Inheritance Site". Famous Silk Road culture provides rich cultural connotation for development of Dunhuang tourism crafts. Local emulating rock paintings, artistic tapestry, duplicate of flying sunk panel, artistic camel and ancient instrument of Dunhuang win great love and enshrinement from people in political and business field and tourists of various places.

With gradual appropriate combination of Buddhist culture and tourism, Nanshan Group spares no effort to explore local religious resource and integrates Buddhist culture into Nanshan's tourism industry. Tourists can appreciate the long history of Buddhist culture when enjoying beautiful and graceful scenery of Lushan. Delivering all living creatures from torment and ideology of quality are spiritual and psychological refuge for people in blatant and restless secular world. At present, there is the world's greatest tin bronze sitting Buddha and China's largest indoor jade Buddha in Nanshan religious historic cultural park. The great Buddha of Nanshan and pharmacist jade Buddha become highlights attracting tourists the most in the scenic spot. Newly built Hua Yan World covers Five Party Five Buddha Hall, turning corridor, pharmacist eulogy pop music spring and other magnificent religious landscapes. In addition, historic cultural park built according to China's dynasty order is like a history book with flesh and blood, displaying long history and extensive and profound local culture. Buddha resource and religious culture are the most precious wealth in our exploitation of local tourism crafts.

In research and development of specific crafts, we need take market as the guidance, consider modern people's psychological need and advanced technology and integrate Buddha culture into works organically. For instance, censer in lotus shape symbolizing noble quality, brush pot, tea set and cups can have large breakthroughs in material, style and artistic features. Bamboo products in pursuit of traditional style can be simple and vigorous in modeling with nostalgic feelings, but their pattern should not be too old-fashioned; Openwork carving works in pursuit of decorative style can make breakthroughs in color and material and can not totally abandon regional culture; Crystal glass works emphasizing on modern style can combine with texture beauty of the material itself and combine artistry with practicability organically. In addition, as to exploitation of crafts, besides making efforts in opening light Buddhism items, like Buddha beads, bodhi, figure of Buddha and musical instruments, Diamond Sutra and Great Compassion Mantra with soul purification function can also manifest cultural connotation of Buddhism. Standing on a small point, deeply exploring its inside information and developing series of crafts from point to area are premise to make it deep and big.

\section{B. Using Advantaged Local Historical Resources}

Nanshan scenic spot is located in Longkou Port, Yantai with outstanding people. It is adjacent to Penglai in the east and faces Tianjin and Dalian across the sea. In ancient times, Longkou is called "ancient Huang County". Due to advantaged geographical advantages, people there become generations of business tycoons with experienced and calm spirit and the spirit of consolidating step by step. Their business expands to three provinces in the northeast of China and even overseas, where comes the name of Chuang Guandong. According to research, there are over 300 money shops and variety shops here, which become typical representatives of Lushang culture. Huang County people stress on the real thing, honest deal and honest spirit in business, and they are also good at using various resources of climate condition, topographical advantages and support of the people. They appropriately apply the way of civil and military from Master Sun's Art of War in commercial activities, stress on traditional doctrine of Confucius and Mencius and obey virtue and morality. Therefore, a series of businessmen with various honors like "Ding Baiwan" - the richest man in Shandong appear. Huang County people's method of doing business can also be regarded as a point of view for us to exploit tourism crafts. Because this kind of culture is deeply rooted in people's heart, while our promoted Buddhist culture is a kind of transplanted resource in the final analysis.

It is just a matter of time that gorgeous turning around of tourism crafts in Nanshan scenic spot will come true with inheritance of ancient Huang County's commercial culture and combination with contemporary new technology, material and idea. Cultural crafts with appreciative and practical function has owned large market for a long time in specific practice, like ivory, gold, bronze and wood. Craft pedants and cinnabar in fan shape, the shape of eight diagrams and cylindric shape and of various sizes like wishful abacus greatly enrich people's spiritual life. What we need to do is applying situational historical resources of Chuang Guandong and Ding Baiwan in the large frame of this kind of crafts and makes it a culture label with good reputation, like Longkou Vermicelli and Yantai apple, thus promoting development of Nanshan's tourism.

\section{Lay Stress on Cultivation of Development and Design Talents}

Competition of the 21 st century is the competition of talent in the final analysis. Development of tourism crafts industry also needs to rely on professional talents with excellent design thought and artistic sensibility. Department of art and design in Yantai Nanshan University which also belongs to Nanshan Group can take the great responsibility. The school should lay stress on theory teaching and encourage students who are familiar with local historical culture and have high comprehensive quality to take part in design and development of tourism crafts, injecting fresh blood into innovation of local tourism crafts through cooperation between school and 
enterprise and combination of production, teaching and research.

In conclusion, in order to exploit branded tourism crafts with regional features in Nanshan scenic spot, besides exploring local Buddhist culture, excellent business and historical resources and cultivating talents of crafts design, we also need to inherit essence of traditional arts and crafts and cooperate with local government in order to achieve healthy development of Nanshan tourism crafts industry and promote increase and rapid rising of tourism economy.

\section{REFERENCES}

[1] Zhang Huixia. Strategic Research on Shanxi's Tourism Resource Development[J]. Economic Geography. 2003(6)

[2] Han Jun. Design Requirement for Tourism Crafts[J]. Xinjiang Arts Institute Journal. 2005 (3).

[3] Jiang Xiaopu and Xu Bin. Design and Market Development of China's Tourism Crafts[J]. Tourism Economy. 2008(7). 